
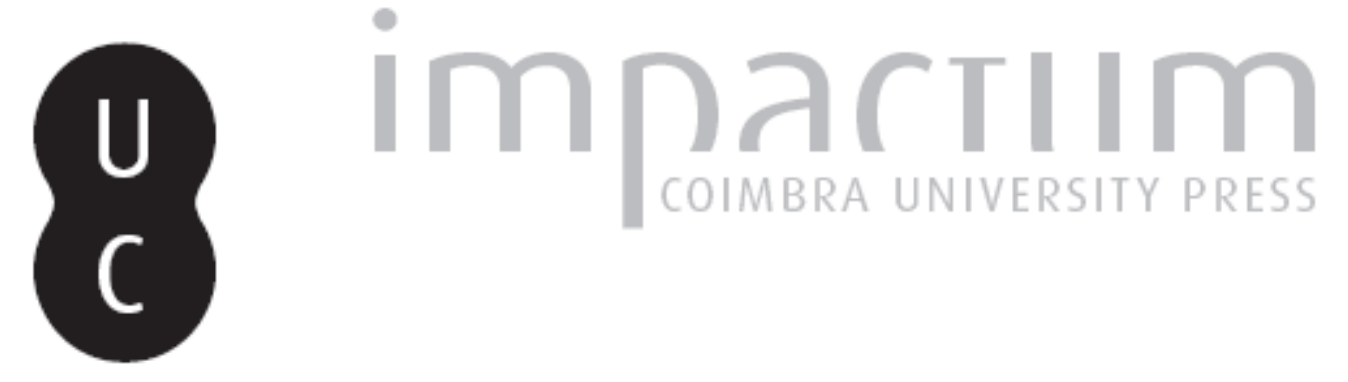

\title{
[Recensão a] J. C. Edmondson, Two industries in Roman Lusitania: mining and garum production
}

\author{
Autor(es): $\quad$ Alarcão, Jorge de \\ Publicado por: Imprensa da Universidade de Coimbra \\ URL \\ persistente: \\ URI:http://hdl.handle.net/10316.2/45577 \\ DOI: \\ DOI:https://dx.doi.org/10.14195/1647-8657_28_13
}

Accessed : $\quad$ 26-Apr-2023 05:47:55

A navegação consulta e descarregamento dos títulos inseridos nas Bibliotecas Digitais UC Digitalis, UC Pombalina e UC Impactum, pressupõem a aceitação plena e sem reservas dos Termos e Condições de Uso destas Bibliotecas Digitais, disponíveis em https://digitalis.uc.pt/pt-pt/termos.

Conforme exposto nos referidos Termos e Condições de Uso, o descarregamento de títulos de acesso restrito requer uma licença válida de autorização devendo o utilizador aceder ao(s) documento(s) a partir de um endereço de IP da instituição detentora da supramencionada licença.

Ao utilizador é apenas permitido o descarregamento para uso pessoal, pelo que o emprego do(s) título(s) descarregado(s) para outro fim, designadamente comercial, carece de autorização do respetivo autor ou editor da obra.

Na medida em que todas as obras da UC Digitalis se encontram protegidas pelo Código do Direito de Autor e Direitos Conexos e demais legislação aplicável, toda a cópia, parcial ou total, deste documento, nos casos em que é legalmente admitida, deverá conter ou fazer-se acompanhar por este aviso.

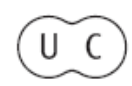


FACULDADE DE LETRAS

INSTITUTO DE ARQUEOLOGIA

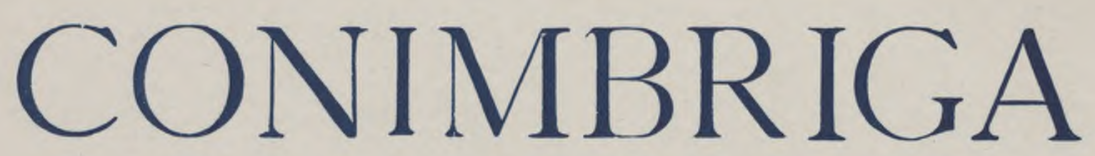

VOLUME XXVIII

UNIVERSIDADE DE COIMBRA

1989 
J. C. EDMONDS ON, Two industries in Roman Lusitania: mining and garum production, Oxford, 1987 (BAR International Series 362), I voi., 355 p.

+12 inum., ilustrado.

O autor pretende, não apenas inventariar as minas e cetárias romanas da Lusitânia, mas inserir o estudo da produção de metais, garum e conservas de peixe num estudo mais global da economia da província.

O problema da propriedade das minas lusitanas é difícil de resolver, por falta da dados. As duas leis conservadas de Vipasca (Aljustrel) demonstram, inequivocamente, que a propriedade destas minas era estatal (ou imperial) e que a área constituía um couto mineiro independente da civitas de Pax Iulia, em cujo território Vipasca se situava. A propriedade estatal das minas de Aljustrel não excluía a iniciativa privada na exploração; renunciando à gestão directa, o Estado arrendava a exploração por meio de concessões.

O regime de propriedade e exploração documentado em Aljustrel não seria, certamente, a regra. Edmondson inclina-se (e, a nosso ver, muito justamente) para a hipótese de uma grande parte das minas (pelo menos, as de pequenas dimensões) ser de propriedade privada. Situadas num fundus, estas minas seriam exploradas pelos proprietários das respectivas villae.

O autor põe, assim, o problema da relação entre a grande propriedade fundiária e a exploração industrial mineira. Na medida em que essa relação não pode esclarecer-se por fontes literárias ou epigráficas, procura uma resposta confrontando a implantação ou distribuição geográfica de villae e minas: elabora uma carta das villae, mapas das minas e uma lista de villae situadas nas vizinhanças de explorações mineiras ou nas quais se têm encontrado escórias (p. 74-75).

A ideia de que os grandes proprietários da terra investiam na exploração de minas situadas em terreno próprio ou procuravam obter concessões em minas estatais parece-nos correcta; mas a pesquisa de villae nas proximidades de minas parece-nos caminho pouco fecundo que não conduz (como, aliás, o autor reconhece) a nenhuma conclusão segura.

Edmondson não pôde aproveitar dados recentes da investigação. Os castella do Baixo Alentejo, aos quais ainda se refere como postos militares situados num caminho entre as minas de Vipasca e o porto fluvial de Mértola, são, afinal, villae fortificadas instaladas no século I a. C. (W A HL, in Madrider Mitteilungen, 26, 1985, p. 149-176), villae que exploravam pequenas jazidas de prata e cobre (MAIA, in Madrider Mitteilungen, 27, 1986, p. 195-223). Aqui, sim, temos um dado arqueológico importante confirmativo do interesse de proprietários fundiários na exploração mineira. Só que os castella, situados geralmente em terreno pouco fértil, não parecem corresponder a grandes unidades de exploração agrária.

A investigação sobre a natureza dos investidores poderia ter sido levada mais longe. O número de libertos cujas inscrições funerárias se encontraram em Pax Iulia é considerável, dando a esta cidade um perfil social muito diferente do de Évora ou Conimbriga, por exemplo. Que fariam esses 
libertos? Não terão, muitos deles, sido os concessionários da exploração de Vipasca?

A nossa pergunta não significa uma contestação da hipótese de Edmondson; apenas sugere uma possibilidade complementar: é muito possível que proprietários de villae e libertos se tenham interessado, uns e outros, por uma exploração que o Estado promovia em regime de concessão.

Os resultados de prospecções luso-francesas realizadas na área da Vidigueira (ainda inéditas, a publicar no relatório das escavações de S. Gucufate) deixam-nos dúvidas sobre a existência de latifundia na região de Pax Iulia: as propriedades, pelo menos na área prospectada, parecem apenas médias. Por outro lado, as residências (de que S. Gucufate é um exemplo) revelam, por vezes, uma riqueza incompatível com a exploração de uma média propriedade. Seria a exploração mineira, para alguns proprietários de villae, um complemento (ou até o fundamento) de uma riqueza que não podia vir só da terra? Ou deveremos admitir que certos proprietários, não explorando directamente grandes herdades, recebiam rendas de outras villae mais modestas ou mesmo de simples casais?

Da existência de escórias de fundição nalgumas villae, retira Edmondson um argumento a favor da participação desses proprietários em explorações mineiras. Sem um exame mais profundo da natureza e volume das escórias, a interpretação delas é altamente duvidosa. As escórias são frequentes em sítios romanos, villae, casais ou cidades. Em muitos casos, correspondem, não a uma exploração mineira, mas apenas à existência de um pequeno artesanato transformador (como, aliás, o autor também admite, p. 77): muitas villae, por exemplo, teriam o seu ferreiro ou até o seu caldeireiro ; as escórias derivarão de pequenas explorações de minério de ferro que seriam muito frequentes na época romana, tal como na Idade Média ou ainda em épocas mais recentes: o número de topónimos «Ferrarias» em Portugal é considerável e corresponde certamente a uma multiplicidade de pequenas indústrias extractivas que terão mantido, da Idade Média até ao séc. XIX, um modo de exploração artesanal que já se ia a norma na época romana. As nossas dúvidas sobre a interpretação das escórias achadas em villae romanas assentam ainda em casos concretos: na villa romana de $\mathrm{S}$. Gucufate, o maior volume de escórias corresponde, não à época romana, mas ao período de utilização do edifício como convento ou até a época posterior ao séc. XVI ; perto de Abrantes, num sítio chamado Casal de Pedro Ferreiro, onde há abundantes escórias, acham-se alguns materiais romanos que deixam supor ocupação desta época; mas serão romanas as escórias? ou do séc. XII? O Pedro Ferreiro que deu nome ao local deve provavelmente identificar-se com aquele a quem o rei D. Sancho doou, em 1191, a herdade de Ordiais, confinante com o termo de Tomar (Rui de Azevedo et alii, Documentos de D. Sancho I (1174-1211), voi. I, Coimbra, 1979, p. 85-86).

O inventário das minas da Lusitânia apresentado por Edmondson em apêndice constitui uma valiosa síntese de informações dispersas pela bibliografia arqueológica portuguesa e espanhola (incluindo alguma informação inédita que o autor obteve de outros investigadores). Um inventário deste 
tipo não pode deixar de ser provisório (como Edmondson reconhece) : primeiro, porque a carta arqueológica da Lusitânia está atrasada e prospecções sistemáticas ou achados casuais virão a descobrir novas estações; segundo, porque a informação relativa a muitas minas é precária. Os vestígios de minerações antigas são frequentes, mas a atribuição desses vestígios à época romana é, em muitos casos, insegura. Tendo de optar por um critério apresentar tudo quanto tem sido considerado como romano ou seleccionar apenas as minas cuja exploração romana se pode comprovar por achados — Edmondson escolheu o primeiro. A opção é, certamente, legítima, e até a mais recomendável numa obra que se propõe ser uma síntese da informação disponível; mas o autor vai longe de mais na argumentação a favor da romanidade de certas minas, que considera romanas só porque nas vizinhanças se encontraram vestígios dessa época. A «vizinhança» não é quantificada. Certos vestígios romanos seguros que são argumento a favor da cronologia romana de algumas minas estão, afinal, demasiadamente distantes paia que a relação proposta possa ser convincente. Nos casos em que a proximidade é evidente, a ausência de um exame dos vestígios pré-romanos ou medievais eventualmente existentes torna a proposta igualmente duvidosa: se houver vestígios pré ou pós-romanos, a cronologia pré-histórica ou medieval da mina em questão é igualmente possível.

Mais do que uma crítica, esta nossa observação constitui uma advertência. Concordamos na vantagem de, em obra monográfica de síntese, se inventariarem vestígios «antigos» ainda que não comprovadamente romanos; mas é necessário que estas minas duvidosas (bem como a área envolvente) sejam no futuro objecto de prospecção sistemática, atenta não apenas aos vestígios de época romana, mas aos de qualquer outro período.

$\mathrm{Na}$ área da Lusitânia que hoje integra o território português, os vestígios de exploração aurífera aluvionar são abundantes no vale do Tejo e no curso de alguns dos seus afluentes a montante da foz do Zêzere. Edmondson parece considerar esta grande área, onde as explorações se estendem por vezes por vários quilómetros quadrados, como um couto mineiro estatal (p. 35). Não obstante as referências literárias clássicas à riqueza aurífera do Tejo, a prudência recomenda que se não tomem, à partida, todos os vestígios como romanos; por outro lado, e apesar da tendência, manifesta desde a época de Augusto, para a apropriação estatal das minas de ouro, não devemos excluir a possibilidade de explorações privadas, ainda que muito vigiadas para que se não perdessem os réditos fiscais e para que os industriais dessem preferência ao Estado na venda do ouro explorado.

A cronologia das explorações mineiras da Lusitânia é difícil de precisar, por falta de dados. A opinião de Edmondson, de que os Romanos se interessaram pela exploração ainda na época republicana (p. 422), parece-nos aceitável; só não concordamos com a utilização dos tesouros de denários republicanos como argumento a favor dessa cronologia. Mesmo quando achados em áreas onde também se localizam minas, os tesouros de denários republicanos parecem representar, na maioria dos casos, tesouros públicos de castros e 
não tesouros particulares de colonos itálicos ou romanos estabelecidos na Lusitânia. É certo que o problema da propriedade dos tesouros é distinto da questão da sua origem. O numerário que integrava os tesouros, fossem estes públicos ou particulares, havia de ser obtido de alguma forma; mesmo sendo públicos os tesouros, o numerário poderá ter resultado da venda, aos Romanos, de metal explorado por populações castrejas. A verdade, porém, é que num período de guerra, como foi o republicano, os tesouros podem ter sido constituídos por saques, designadamente em operações militares vitoriosas dos indígenas contra os Romanos ou contra determinadas cidades filo-romanas. O tesouro do castro de Alvarelhos, que o autor parece considerar como o aforro resultante de actividade mineira (p. 39), integrava algumas bolas de prata, duas delas marcadas com a palavra Caesar. Ainda que seja passível de outra interpretação, este tesouro, cuja última moeda data de 27 a. G. pode representar um saque de qualquer corpo expedicionário romano actuante na área durante as campanhas de Augusto no Noroeste.

No capítulo IV, Edmondson trata das consequências da exploração mineira. Uma delas foi a imigração interna, decerto muito mais vasta do que aquela que se pode comprovar por algumas raras lápides funerárias de indivíduos deslocados (lápides recenseadas nas p. 62-63). Não nos parece, ao contrário do que o autor diz (p. 61), que a deslocação dos Lusitanos para a margem esquerda do Tejo, referida por Estrabão e agora documentada pelo estudo onomástico realizado por José d'Encarnaçâo, se possa explicar pela exploração mineira na área; nem tão pouco, como já vimos, se pode defender a ideia de que os castella do Baixo Alentejo correspondam a postos militares destinados a vigiarem uma mão-de-obra parcialmente hostil (p. 61 e 69). Por outro lado, parece-nos duvidoso explicar o sodalicium Bracarorum de Pax Iulia como uma associação de imigrantes envolvidos na exploração mineira ou interpretar Castra Caepiana como um acampamento para vigiar a exploração aurífera do Tejo (p. 70). Também nos não parece correcto (embora tenhamos, em tempo, defendido essa ideia) tomar a inscrição funerária de um praefectus equitum alae I Singularium Civium Romanorum como prova da instalação, em Idanha-a-Velha, de um corpo militar que vigiaria a exploração do ouro da Beira Baixa (p. 70).

Dos vestígios do povoado mineiro de Vipasca e dos materiais encontrados na necrópole, Edmondson conclui pelo baixo nível da vida dos mineiros (p. 85-86). Há, talvez, um certo exagero na afirmação.

Outra consequência da exploração mineira foi a desflorestação, assunto de extremo interesse de que o autor trata nas p. 77-81, com cálculos suficientes para nos fazerem tomar consciência da dimensão do fenómeno. A desflorestação foi talvez um factor determinante na decadência das minas, cuja exploração poderá ter sido reduzida ou mesmo abandonada por falta de combustível para os fornos de fundição.

O peixe salgado (salsamenta) e os molhos de peixe usados como condimento (garum $_{i}$ liquamen, muria, bailee) representaram uma das principais exportações da Hispânia e, de modo particular, da Lusitânia. Em setenta e 
oito naufrágios mediterrânicos de embarcações procedentes da Península Ibérica, ocorridos entre 50 a. C. e 250 d. C., cerca de $66 \%$ da carga era constituída por ânforas de garum (ou de salsamenta). Cálculos efectuados em Òstia, o grande porto abastecedor de Roma, confirmam a importância da exportação hispânica para a Itália. A venda foi manifestamente menor para a Bretanha, talvez, como observa Edmondson, por razões culturais: seria menor, aqui, o gosto pelo garum (p. 104).

Qual o regime de propriedade da indústria do garum: estaria esta nas mãos de particulares? haveria, pelo menos nalguns casos, propriedade estadual ou municipal da indústria? seriam a pesca e o fabrico de salsamenta e de garum direitos estatais ou municipais exercidos por particulares em regime de concessão? O assunto é discutido por Edmondson, aliás com referências a outras regiões do Império e a outras épocas históricas para além da romana (p. 116-117). A ausência de dados impede quaisquer conclusões, paia além da certeza de que os particulares exerciam a indústria e da probabilidade de esta ter constituído, através de taxas, fonte de receitas fiscais para o Estado ou para a administração local.

Tróia foi um dos maiores centros conserveiros da Antiguidade, comparável a Baelo, na Bética. Noutros centros urbanos da Lusitânia, como Olisipo, Gaetobriga, Sines, Ossonoba, Balsa e Baesuris, há vestígios desta mesma indústria, embora os achados sejam insuficientes para se avaliar a sua importância. Por outro lado, têm-se reconhecido cetárias em diversas villae do litoral algarvio e da foz do Sado. A área escavada destas villae não permite saber se o garum era preparado em pequena escala, apenas para consumo próprio ou de um mercado local, ou se representava uma produção considerável destinada à exportação que, neste caso, se faria pelo porto de Tróia e, para o Algarve, pelo de Ossonoba. Também se não pode demonstrar a hipótese de Edmondson, de que, nas villae, a preparação do garum ocupava a mão-de-obra rural, mais vaga durante os meses de Verão, exactamente aqueles em que a actividade industrial se concentrava.

No centro urbano de Tróia, cuja instalação Edmondson data dos fins do séc. I a. C. (embora esta data nos pareça discutível, tendendo nós a atribuir a fundação do povoado a data posterior mas, de qualquer forma, no decurso da primeira metade do séc. I d. C.), a actividade industrial não era compatível com trabalhos rurais porque os solos da península não eram favoráveis à agricultura : ou, na ocasião em que a pesca e a preparação do garum se concentravam, havia deslocação de trabalhadores rurais do interior, ou a indústria era praticada por uma população permanentemente residente. Neste caso, porém, que actividades poderiam ocupar a população nos meses de Inverno? Edmondson apresenta uma sugestão de interesse: a colheita de murex e de purpura haemastoma, a preparação dos tintos e a própria tinturaria dos tecidos ocupariam parte da população nos meses de Inverno e no início da Primavera, antes de começar a grande safra da pesca.

As escavações de Tróia têm sido, até agora, demasiadamente reduzidas para resolver este e outros problemas que a estação nos põe. Entre eles, o da 
propriedade das indústrias: essas seriam pequenas empresas, eventualmente constituídas ou agrupadas em sociedades cooperativas? ou grandes indústrias, segundo um modo de produção que poderíamos classificar de «capitalista»? A riqueza de certas habitações da cidade e dos materiais arqueológicos recolhidos (entre eles, boa sigillata e sigillata clara e vidros caros) inclinam-nos para a segunda hipótese.

Baseado em estatísticas recentes, Edmondson chama a atenção para consideráveis flutuações, de ano para ano, na tonelagem de pescado nas costas portuguesas. Estas flutuações poderão ter criado, se não crises, pelo menos variações importantes de produção. As consequências de tais variações no mercado seriam, segundo o autor, minimizadas (e os preços mantidos razoavelmente constantes) por um sistema regulador de abastecimento: os produtores ou abastecedores poderiam guardar a produção de anos abundantes para colocarem no mercado em anos fracos. É possível que Edmondson tenha razão: mas, na época romana, terão sido as flutuações do pescado tão grandes como hoje? Por outro lado, as flutuações só têm impacto a partir de um certo nível industrial: mais ou menos abundante, de ano para ano, talvez o peixe fosse sempre suficiente para abastecer as indústrias romanas, cujas necessidades de matéria-prima poderiam ter ficado sempre abaixo dos recursos disponíveis mesmo em anos de relativa escassez de peixe. Em terceiro lugar, talvez as estatísticas globais não possam considerar-se representativas de eventuais flutuações nas áreas em que se situam as cetárias romanas; por outras palavras, a variação anual dos recursos de peixe no litoral algarvio e na foz do Sado poderia ser menor do que a variação global ao longo da costa portuguesa.

A produção muito considerável de garum na costa portuguesa exigia o fabrico de ânforas e a existência de armadores que assegurassem o transporte.

O capítulo que Edmondson apresenta sobre as ânforas lusitanas (a título, aliás, e como diz, provisório e mais com intenção de encaminhar do que de resolver o assunto) está ultrapassado por recentes descobertas posteriores à redacção desta obra. De qualquer forma, e tendo em conta a informação disponível na data em que a obra foi publicada, o capítulo representa uma actualização notável dos nossos conhecimentos sobre a produção de ânforas lusitanas.

A primeira ânfora de garum indiscutivelmente lusitana é uma variante do tipo Dressel 14. A sua produção não parece ter começado antes de meados do séc. I d. G. O garum fabricado na primeira metade do século pode ter circulado em ânforas do tipo Dressel 7/11, tão semelhantes às produzidas na Bética que, até agora, não foi possível identificá-las. O tipo Dressel 14 foi produzido na foz do Bado e no Algarve (designadamente em S. Bartolomeu de Castro Marim). Edmondson não regista marcas; conhecem-se todavia várias: MA.MV.S; T.M.G.; G.I.P. ; L.I.A. ; LV///; BP; MO.

O fabrico desta variante lusitana do tipo Dressel 14 continuou até aos fins do séc. II ou aos inícios do III, coexistindo então com o tipo Almagro 50. A produção deste segundo tipo está atestada na foz do Sado, mas é possível que se tenha realizado também no Algarve. Edmondson apresenta uma útil lista

Conimbriga, 28 (1989), 229-252 
das marcas presentes neste tipo e regista a sua ampla distribuição geográfica, que inclui (fora de Portugal) Itália, Ampúrias, Barcino (Barcelona), Òstia, Roma, Alba Fucens, Luni, Roselle (Etrúria), Narbo, Marrocos e Samaria (Palestina).

Outro tipo lusitano, Almagro $51 \mathrm{~A}-\mathrm{B}$, foi fabricado igualmente na foz do Sado, dos fins do séc. Ili aos fins do séc. V d. C.

O tipo Almagro $51 \mathrm{G}$, produzido não só nos fornos do Sado mas também no Algarve, começou ainda no séc. Ile continuou até ao IV.

O capítulo é completado com um inventário extenso de lugares onde estes diversos tipos têm sido encontrados e ilustrado com mapas de distribuição.

Além destes quatro tipos de ampla difusão, há diversos outros, particularmente algarvios, que parecem ter tido uma circulação muito restrita, possivelmente (como Edmondson sugere) porque correspondem a pequenas produções.

Sobre os transportes sabemos, por enquanto, muito pouco. Edmondson regista as duas únicas inscrições romanas de Portugal que têm sido apresentadas como testemunhos da existência de armadores: GIL II 25 e 260. A primeira foi encontrada em Mirobriga e a segunda, em Armés (Sintra), no território de Olisipo. Num recente estudo, Cardim Ribeiro demonstrou que L. Iulius Maelo Gaudicus, citado nesta última, não foi, afinal, um armador (Sintria, I-II, 1982-1983, p. 151 s.).

Em face desta pobreza de elementos, podemos perguntar-nos se a produção da Lusitânia era transportada por armadores mesmo lusitanos ou por negociantes não residentes na província. O grande porto bético de Gades poderia ser, como sugere Edmondson, pelo menos de início, o empório para o qual o garum da Lusitânia era transportado em pequenas embarcações, sendo aí transferido para navios de maior tonelagem. O testemunho de algumas embarcações naufragadas, com uma carga exclusiva ou maioritariamente constituída por ânforas lusitanas, sugere, porém, a existência de um transporte directo da Lusitânia para o Mediterrâneo central, possivelmente para Òstia; mas, mesmo no caso de transporte directo, seria este assegurado por armadores lusitanos ou itálicos?

Pelos problemas que claramente formula, as relações que estabe ${ }^{\wedge}$ ce entre produção e fiscalidade ou produção agrária e industrial, pelos inventários de minas, cetárias, fornos e ânforas, esta obra constitui uma importante síntese da mineração e da piodução do garum na Lusitânia. As reservas que num ou noutro ponto formulámos não diminuem o valor do trabalho. É pena, todavia, que no inventário das minas e cetárias, Edmondson não tenha desenvolvido as observações e notas críticas, distinguindo mais claramente o incerto do seguro. Poucos leitores irão refazer a pesquisa bibliográfica ou conferir as citações. Facilmente os sítios aqui apresentados passarão para obras futuras como estações confirmadas. Ora, como genericamente já observámos, a cronologia romana de muitas minas é extremamente insegura. As minas P 01, $02,06,10,12,15,17,19,20,22,35,37, \mathrm{~S} \mathrm{30}, 33$ têm vestígios de trabalhos «antigos» mas não necessariamente romanos. Os Furados de Pombeiro, S 42, 
são medievais. Os pontos $\mathrm{P}$ 07, 16 e 46 não parecem corresponder a minas concretas, mas a grandes áreas nas quais se localizam diversas minas, aliás de cronologia incerta. Quase todas as explorações aluviais de ouro e de estanho registadas no conventus scallabitanus são incertas por falta de materiais claramente associados, embora a sua atribuição à época romana nos pareça provável. As estações P 37 e 38 devem reduzir-se a uma só, na qual é manifesta a exploração medieval, mas não a romana. Diversas referências bibliográficas apontadas revelam cepticismo ou cautela quanto à cronologia romana, facto que o autor não salientou devidamente. Há ainda um ou outro erro de integração administrativa.

Relativamente às cetárias, a estação G 01 deve ser desdobrada em duas, Ilhéu da Baleeira e Forte de Beliche; a bibliografia citada por Edmondson não regista, porém, cetárias em nenhum destes pontos. A estação C 05 deve ser suprimida e substituída por Lagos, cidade onde se encontraram cetárias junto ao Hospital Militar. Os vestígios referidos em C 15A não devem corresponder a cetárias, visto que no Largo da Sé, em Faro, se situava o forum de Ossonoba. Os tanques referidos em G 17, 23, 28 e 38 devem ser considerados com suspeição. Os tanques de G 24 são geralmente considerados como tanques de tinturaria e não de salga.

Jorge de Alarcão

William R. BIE Rs, Mirobriga. Investigations at an Iron Age and Roman site in southern Portugal by the University of Missouri-Columbia, 1981-1986. Com contribuições de Jane G. Biers, Albert Leonard Jr., Kathleen Warner Siane, Maura F. Gorman e Craig E. Order. British Archaeological Reports, International Series, 451, Oxford, 1988, 1 vol., 244 p. -h 297 figs.

O volume agora editado constitui relatório parcial das escavações realizadas em Mirobriga pela Universidade de Missouri - Columbia.

A área escavada de Mirobriga é relativamente reduzida (2,8 hectares). Inclui uma acrópole cujo significado se mantém duvidoso (forum ou santuário?), diversos edifícios parcialmente escavados ao longo das ruas que descem pela encosta, duas termas na base dela e um circo. Os investigadores americanos realizaram o primeiro levantamento topográfico completo do sítio e este é, sem dúvida, um dos mais importantes contributos que a obra nos traz.

A distância entre a acrópole e o circo é considerável: mais de 600 metros. Assim, impunha-se pelo menos uma batida sistemática do terreno entre o núcleo urbano conhecido e o circo, de modo a detectar eventuais vestígios de 